\title{
Management of glaucoma as a neurodegenerative disease
}

Gurjeet Jutley², Sheila MH Luk³ ${ }^{3}$ Mohammad H Dehabadi, ${ }^{1,3}$, M Francesca Cordeiro ${ }^{1,2,+}$

${ }^{1}$ Glaucoma \& Retinal Neurodegeneration Research Group, Visual Neuroscience, UCL Institute of Ophthalmology, London, UK

${ }^{2}$ Western Eye Hospital, Imperial College Healthcare Trust, London, UK

${ }^{3}$ Moorfields Eye Hospital NHS Foundation Trust, London, UK

+Author for correspondence:

Tel: +44 2076086938

Fax: +44 2076086939

m.cordeiro@ucl.ac.uk 


\section{Practice Points:}

- Glaucoma is considered a neurodegenerative disease due to its pathophysiology of progressive retina ganglion cell (RGC) and axon degeneration and RGC death which $^{2}$ leads to functional impairment and in most severe case, blindness.

- There are multiple approved topical therapies with IOP lowering effects used in the treatment of glaucoma. The most common mechanism of these topical treatments is to either suppress the production of aqueous humour, or increase the outflow pathways.

- $\quad$ Some patients disease progresses despite well-controlled IOPs, demonstrating that IOP alone does not explain the pathogenesis of this complex neurodegenerative disease. Putative mechanisms include oxidative stress and apoptosis, similar to that seen in Alzheimer's disease.

- There are a small number of commercially available agents for the treatment of glaucoma, which have shown promise in possessing potential neuroprotective effects.

- Clinical research has an emphasis on: neuroprotection (delaying or preventing the apoptosis of RGC's), and neuro-recovery (reversing the process of RGC apoptosis).

- Important modulatory cascades that can be manipulated are rho-associated coiled coil-forming protein kinase, renin-angiotensin system, endothelin, nitric oxide and adenosine.

- An explosion of interest has accrued on immune-modulation, stem cell therapy and neural regeneration, with exciting developments expected in the not too distant future. 


\section{Abstract:}

Glaucoma is a neurodegenerative disease with an estimated prevalence of 60 million people, and the most common cause of irreversible blindness worldwide. The mainstay of treatment has been aimed at lowering intraocular pressure, currently the only modifiable risk factor. Unfortunately, despite adequate pressure control, many patients go on to suffer irreversible visual loss. We first briefly examine currently established IOP lowering treatments, with a discussion of their roles in neuroprotection as demonstrated by both animal and clinical studies. The review then examines currently available IOP-independent agents that have shown promise for possessing neuroprotective effects in the management of glaucoma. Finally, we explore potential future treatments such as immune-modulation, stem cell therapy, and neural regeneration as they may provide further protection against the neurodegenerative processes involved in glaucomatous optic neuropathy. 


\section{Key Words:}

Glaucoma, Neuroprotection, Neuromodulation, Stem Cell Therapy 


\section{Introduction}

Glaucoma, the commonest irreversible cause of blindness worldwide, has an estimated prevalence of 60 million people, leading to 8.4 million people with blindness as a result. These figures have been projected to increase to 80 million and 11.2 million respectively, by 2020 [1]. It is a disease with an optic neuropathy characterized by optic disc cupping and visual field loss. It has been considered a neurodegenerative disease due to its pathophysiology of progressive retina ganglion cell (RGC) and axon degeneration and RGC death $[2-4]_{L}$ which leads to functional impairment and in most severe case, blindness.

Glaucoma classification can be carried out in different ways, but is most commonly based on drainage angle morphology and any secondary causes of the disease. If an elevated intraocular pressure (IOP) is present without glaucomatous damage, it is termed ocular hypertension $(\mathrm{OHT})$. In the case of glaucoma with low IOP, it is termed normal tension glaucoma (NTG).

Currently, most of the treatment modalities are based on lowering the IOP, the only successfully modifiable risk factor that has been identified. However, there are some patients whose disease progresses despite well-controlled IOPs, demonstrating that IOP alone does not explain the pathogenesis of this complex neurodegenerative disease $[5,6]$. These observations suggest that other, non-IOP dependent factors may play a significant role in the pathophysiology of glaucoma, and have thus attracted much research in search of novel approaches to glaucoma management. 
Studies have shown that the glaucoma-associated neurodegeneration process is not limited to the optic nerve, but involves the whole visual pathway extending to the lateral geniculate nucleus and visual cortex [7-9], as demonstrated by MRI imaging showing a reduction in height and volume of the LGN in subjects with POAG [10] and NTG [11]. Similarly, fMRI studies have confirmed alterations in the visual cortex that correlate with the visual field changes observed in glaucoma $[10,12]$.

In this review, we will summarise current treatment modalities of glaucoma, and their links to neurodegeneration, as well as possible neuroprotection pathways and current trials exploring the management of glaucoma as a neurodegenerative disease. 


\section{Commonly used anti-hypertensive agents:}

Intraocular pressure is determined by the balance between the aqueous humour synthesis and its rate of outflow. Aqueous is produced by the non-pigmented cells of the ciliary body epithelium, flowing in a retrograde manner anteriorly through the pupil to the trabecular meshwork (TM). The resistance to this outflow pathway at the trabecular meshwork increase with age, and can lead to an IOP increase and primary open angle glaucoma (POAG).

There are multiple approved topical therapies with IOP lowering effects used in the treatment of glaucoma. The most common mechanism of these topical treatments is to either suppress the production of aqueous humour, or increase the outflow pathways. The major established classes of IOP-lowering drugs are beta-adrenergic blockers (BB), alphaadrenergic agonists (AA), carbonic anhydrase inhibitors (CAI), and prostaglandin analogues (PGA).

\section{Beta-blockers}

Beta-blockers (BBs) were once the gold standard topical treatment before PGAs, as they achieved good IOP-lowering effect with relatively limited ocular side effects. While no longer the first line agent in use, BBs are still frequently used as a combination therapy agent with other classes of drug. BBs block sympathetic $\beta$-adrenocepters on the ciliary epithelium and elicit their IOP lowering effect by reducing aqueous production. [13]. This treatment may not be suitable for patients with co-existing respiratory and cardiac pathology due to the systemic side effects. 
Beyond IOP reduction, there is a small body of evidence that BBs may harbour IOP independent neuroprotective effects, perhaps through up-regulation of brain derived neurotrophic factor (BDNF) $[14,15]$, or by modulation of vasculature which may temper ischemia-induced RGC injury [16].

\section{Prostaglandin Analogues}

Clinically, Prostaglandin Analogues (PGAs) have become the first line treatment recommended by national guidelines, due to the advantages of once-daily administration and relatively low side-effect profile [17]. Most PGAs used in the treatment of glaucoma are PG F2 $\alpha$ analogues, which act via the $\mathrm{G}$ protein-coupled receptor family to stimulate aqueous outflow by several fold via the uveoscleral pathway [18]. Bimatoprost, Latanopost, and Travorpost have been shown to increase uvealscleral outflow in different groups of glaucoma patients, including ocular hypertension, HTG and NTG [19-22].

Although a handful of in vitro animal studies have suggested PGAs to exhibit a direct and IOP independent neuroprotective effect in RGCs by reducing apoptosis [23-25], no other supporting evidence for this has been published.

\section{Carbonic Anhydrase Inhibitors}

Carbonic Anhydrase Inhibitors (CAIs) reduce IOP by inhibiting carbonic anhydrase, a critical enzyme required for aqueous humour production, noncompetitively and reversibly at the ciliary body epithelium in the posterior chamber. Their action leads to a reduction of bicarbonate ions, hence reducing sodium and fluid transportation, and aqueous formation [26]. Both topical and oral preparations are used in the management of glaucoma. 
In addition to their IOP lowering properties, CAls have also been shown to improve blood flow in the retina due to vasodilatory effects which lead to increased retrobulbar blood flow $[27,28]$. Although the reduction of optic nerve head circulation has been demonstrated in both POAG and NTG patients [29], there is no evidence that the vasodilatory effect of CAIs produces any additional neuroprotective effect independent of IOP.

\section{Currently available agents with potential neuroprotective effects:}

There are a small number of commercially available agents for the treatment of glaucoma, which have shown promise in possessing potential neuroprotective effects.

\section{Brimonidine:}

Brimonidine is a highly selective alpha2- adrenergic agonist that was approved by the FDA for the treatment of glaucoma in 1996. It acts to suppress aqueous formation by adenylate cyclase inhibition, and to increase uveoscleral outflow by increasing prostaglandin release via alpha adrenergic stimulation [30]. Interestingly, beyond the glaucoma drainage apparatus, $\alpha_{2}$-receptors have also been localised in other ocular sites such as human cadaveric iris and ciliary epithelium [31], as well as in neuronal dendrites, glia, ciliary muscle, retina, retinal pigment epithelium, and the choroid of animal eyes [32].

There has been a strong interest in the neuroprotective actions of Brimonidine, as it is the only topical glaucoma treatment to have shown a promising neuroprotective effect in human clinical trials [33]. In the Low-pressure Glaucoma Treatment Study (LoGTS) involving 178 NTG patients, a similar IOP lowering effect was achieved with Brimonidine $(14.2 \mathrm{mmHg}$, 
$\mathrm{SD}=1.9)$ and timolol $0.5 \%(14.0 \mathrm{mmHg}, \mathrm{SD}=2.6)$. When analysing visual field (VF) progression after four years of treatment however, the authors found that a significantly smaller proportion of the Brimonidine group had VF progression than the Timolol group $(9.1 \%$ vs 39.2\%). This remarkable increased preservation of visual function exhibited by the Brimonidine group implies an IOP independent mechanism for Brimonidine's action. It must be said however that ocular allergy to Brimonidine resulted in significantly higher rates of participant dropout in this group in the first year, which could have masked visual field progression in this group of patients which were not analysed [34]. This higher incidence of ocular allergy also means that any potential protective effect from Brimonidine is only possible for patients who can tolerate the agent.

Multiple in vitro studies have confirmed Brimonidine to be protective against excitotoxic insults to RGCs [35-37]. It has also been shown to protect RGCs against Glutamate mediated excitotoxicity by reducing CAMP dependent intracellular calcium accumulation [38]. In vivo studies have also demonstrated Brimonidine's neuroprotective effects; in a rat glaucoma model, intravitreal Brimonidine was found to significantly increase BDNF concentrations in RGCs, a finding that is perhaps unsurprising due to the multiple ocular sites with alpha-2 adrenergic receptors expression [39]. Other animal studies have also demonstrated Brimonidine's RGC protection properties in the face of different retinal and optic nerve insults such as ischaemia and optic nerve compression [40,41]. A recent study by our group found Brimonidine to significantly reduce RGC apoptosis in vitro, and in vivo glaucoma models through its effects on the amyloid beta pathway [37]. 
Beyond action at the RGC level, anterograde optic nerve axonal transport to the superior colliculus was shown to be restored by Brimonidine in a rat glaucoma model [42]. As axonal dysfunction and degeneration precede neuronal loss $[43,44]$, these supplementary protective mechanisms instigated by Brimonidine may explain its additional IOP independent benefits in preventing visual field progression in adult subjects [33].

\section{Coenzyme Q10}

Coenzyme Q10 (Co-Q10) is a co-factor of the mitochondrial electron transport chain, playing an important role in mitochondrial gene expression, mitochondrial DNA maintenance, and is essential for adenosine triphosphate (ATP) synthesis [45]. As well as being a potent antioxidant, Co-Q10 is thought to prevent the formation of mitochondrial permeability transition pores [46], which are known to be a pro-apoptotic trigger in RGC death following excitatory damage [47]. As such, Co-Q10 has been reported to show neuroprotective effect in other neurodegenerative diseases, such as in Alzheimer's disease (AD) and Parkinson's disease (PD) [48].

Many animal studies have provided promising results for Co-Q10's neuroprotective effects in glaucoma models; It has been demonstrated that intraocular and oral Co-Q10 reduces RGC apoptosis [49], and ameliorates oxidative stress mediated mitochondrial dysfunction in a rat $\mathrm{OHT}$ model [50]. Co-Q10 can also reduce damage from glutamate excitotoxity, and promote RGC survival by preserving optic nerve head axons in glaucomatous mice [51].

A single human clinical has studied the effects of topical Co-Q10 with vitamin E in POAG patients at 1 year using retinal-evoked, and cortical-evoked responses as a measure of visual 
function [52]; the study found that Co-Q10 with vitamin E administration resulted in significantly enhanced inner retinal function (as demonstrated on pattern electroretinogram (PERG) readings), with consequent improvements of the visual cortical responses (as measured by visual evoked potentials (VEP)) when compared to the control group. More over, theses improvements were seen to be independent of age, IOP, and VF changes, confirming these effects to be due to the Co-Q10/vitamin E supplementation [52].

\section{Citicoline}

Citicoline is a major phospholipid in the neuronal membrane that has a crucial role in phosphatidylcholine synthesis [53]. It is also thought to play a role in increasing the metabolism of cerebral structures via facilitating the biosynthesis of phospholipids in neuronal membranes [54], and inhibiting phospholipid degradation [53]. In vitro studies have previously reported data supporting Citicoline's protective effects against apoptosis, and reducing synaptic loss in retinal cell cultures $[55,56]$. Due to these features, Citicoline has been shown to have a neuroprotective effect in conditions such as stroke $[57,58]$ and PD [59].

Randomised controlled trials of intramuscular [54] and topical Citicoline [60] vs placebo in glaucoma patients have demonstrated a significant improvement in retinal function as measured by electrodiagnostics; VEP and PERG were measured as they reflect retinal bioelectric responses and visual cortical responses respectively. Citicoline treatment was found to result in significant improvement in VEP and PERG readings, where the amplitude of responses was increased, together with shortening of times-to-peak, and retinal conduction times. These changes suggest the effects of Citicoline to be both at retinal, and 
at post-retinal visual pathway level. Beyond these initial clinical trials, the same group has presented eight-year follow up data with intramuscular Citicoline treatment, which appears to suggest stabilisation, or even improvement of glaucomatous visual dysfunction as measured by VF stabilisation, and improvements in PERG and VEPs [61]. Long term data with topical Citicoline is awaiting publication [62], while oral Citicoline has also been found to reduce the rate of VF progression in POAG patients [63], and improve visual pathway function as measured by electrophysiological tests [64].

\section{Memantine}

Memantine is an non-competitive glutamate antagonist, which blocks excessive NMDA activity, and has been approved as a treatment for moderate-to-severe Alzheimer's disease [65]. Studies have explored the potential for Memantine in the treatment of glaucoma as a potential neuroprotectant; Pre-clinical animal studies have demonstrated Memantine to have a neuroprotective effect on RGC death in a rat OHT model, as well as an optic nerve injury model [66]. Another animal study suggested that Memantine treatment at the early phases of the glaucomatous process appears to prevent neuronal injury in the retina [67].

These promising animal study results are yet to be replicated in human studies however, with two phase 3 clinical trials involving Mementine in glaucoma patients failing to publish results to confirm its neuroprotective effects thus far. This maybe disappointing, but other second generation Memantine derivatives are in development and may be shown to be beneficial for glaucoma patients in the future [68]. 
The difficulty in translating animal study and early clinical trial results to clinical practice in glaucoma and other neurodegenerative disease is not an uncommon problem [69]. This may in part be due to difficulties in quantifying disease progression in a slow progressing, multifactorial disease. In neuroprotection studies for example, where the focus is the prevention of functional damage in patients, recruitment of patients with established disease may not allow the demonstration of maximum effects of the agent being tested. Another stumbling block is that currently one of the common measurable outcomes in glaucoma studies is based on visual field progression. This measurement method is limited by patient performance variability, learning effect, and more importantly may not be sensitive enough to detect small treatment effects in neuroprotection trials. Detecting these subtle effects would require very large cohorts, and possibly a lengthy trial to demonstrate therapeutic benefits for a slowly progressive disease. 


\section{Novel therapies, and neuroprotection in glaucoma treatment:}

As a result of the search for IOP independent approaches to glaucoma treatment in recent years, there has been an explosion of exciting research exploring potential molecules contributing to the aetiology of glaucomatous optic neuropathy. The importance of this ongoing research and development in neuroprotection is highlighted by patients who's disease progresses to blindness despite maximally tolerated hypotensive medications or surgical procedures. Quite simply, the emphasis is on:

- Neuroprotection, preventing or delaying the apoptosis of RGC's

- Neuro-recovery, reversing the process of RGC apoptosis

We have summarised the various aetiologies leading to the endpoint of glaucomatous optic neuropathy and the studies citing evidence in targeting these mechanisms in Table 1 . These studies are discussed in further details in the following sections.

Table 1:

\section{Mechanism}

\section{Mediators \&} targets

\section{Pre-clinical studies}

Clinical studies 


\begin{tabular}{|c|c|c|c|}
\hline $\begin{array}{l}\text { Smooth muscle } \\
\text { contraction at the } \\
\text { Trabecular Meshwork }\end{array}$ & ROCK & $\begin{array}{l}\text { Honjo M [70], Rao PV } \\
\text { [71], Delaney Y [72], } \\
\text { Grieshaber MC [73], } \\
\text { Kandabashi T [74], } \\
\text { Chrissobolis S [75], } \\
\text { Kitaoka Y [76], Bertrand } \\
\text { J [77], Bertrand J [78], } \\
\text { Honjo M [79], Okumura } \\
\text { N [80], Waki M [81], } \\
\text { Thieme H [82] }\end{array}$ & $\begin{array}{l}\text { Tanihara H [83], } \\
\text { Nakajima E [84], } \\
\text { Wang R [85], } \\
\text { Mizuno K [86], Chen } \\
\text { J [87] }\end{array}$ \\
\hline $\begin{array}{l}\text { Ischaemia due to } \\
\text { vasoconstriction }\end{array}$ & $\begin{array}{l}\text { ET, Adenosine, } \\
\text { RAS }\end{array}$ & $\begin{array}{l}\text { Renieri G [88], } \\
\text { Ehrenreich H [89], } \\
\text { Yagami T [90], Yagami T } \\
\text { [91], Zhang M [92], } \\
\text { Galvao J [93], Wang RF } \\
\text { [85], Inoue T [94], Yang } \\
\text { H [95], Cullinane AB } \\
\text { [96], Kramkowski K [97], } \\
\text { Santos RAS [98], } \\
\text { Vaajanen A [99] }\end{array}$ & Costagliola C [100] \\
\hline Pleomorphic activity & NO & $\begin{array}{l}\text { Nathanson JA [101], } \\
\text { Garcia E [102] }\end{array}$ & \\
\hline Apoptosis & $\begin{array}{l}\text { Caspases and } \\
\text { PERK/CHOP }\end{array}$ & $\begin{array}{l}\text { McKinnon SJ [103], Guo } \\
\text { L [104], Doh SH [105] }\end{array}$ & \\
\hline $\begin{array}{l}\text { Immune-modulated } \\
\text { neurotoxicity }\end{array}$ & $\begin{array}{l}\text { Exaggerated } \\
\text { complement } \\
\text { response }\end{array}$ & $\begin{array}{l}\text { Bonifati DM [106], Tezel } \\
\text { G [107], Ding QJ [108], } \\
\text { Howell GR [109] }\end{array}$ & \\
\hline $\begin{array}{l}\text { Oxidative stress \& } \\
\text { mitochondrial } \\
\text { dysfunction }\end{array}$ & $\begin{array}{l}\text { ROS mediated } \\
\text { damage }\end{array}$ & $\begin{array}{l}\text { Osborne NN [110], Tezel } \\
\text { G [107], Ju WK [111], } \\
\text { Tezel G [112], Huang J } \\
\text { [113], Barber AJ [114], Li } \\
\text { J [115] }\end{array}$ & \\
\hline
\end{tabular}

Table 1: Various mechanisms leading to the endpoint of glaucomatous optic neuropathy and the studies citing evidence in targeting each mechanism

Rho-associated coiled coil-forming protein kinase (ROCK) Inhibitors:

A number of studies have explored Rho signalling in the TM; Rho is a GTPase enzyme involved in cytoskeletal rearrangement and smooth muscle contraction, being facilitated further down the signalling pathway by specific GTPases called Rho-associated coiled coilforming protein kinase (ROCK) [116]. Two human isoforms of these serine/threonine kinases 
are present, ROCK 1, and ROCK 2, being expressed in both the CM and TM. Specifically, ROCK is involved in myosin light chain (MLC) phosphorylation, with the cycle of phosphorylation/dephosphorylation responsible for contraction and relaxation of smooth muscle. Manipulation of this process represents a novel form of anti-hypertensive drug and indeed, both laboratory \& animal studies have proposed the following mechanisms of action [70-80]:

- Improving blood flow to the ON

- Neuroprotection of healthy ganglion cells

○ Relaxing TM tissue

The predominant mechanism by which ROCK inhibtors exert their clinical effects are decreasing outflow resistance by modulating cytoplasmic fibres [117], and hence increasing the outflow via the conventional route. It is also important to note that as well as via ROCK mediated signalling, phosphorylation of this MLC complex is achieved by calcium mobilisation [118].

A multitude of animal studies have shown that one ROCK inhibitor, Y-39983 relaxes both the CM and TM, leading to a reduction in IOP $[70,71,81,82]$. Tokushige at al compared Y-39983 to another ROCK inhibitor Y-27632 in both albino rabbits and cynomolgus monkeys [119]. Y39983 proved to be the more stable compound of the two, inhibiting ROCK more potently, and clinically resulting in an increased outflow and hence reduced IOP [119]. Interestingly, whilst the maximal IOP reduction achieved in rabbits was $13.2+/-0.6 \mathrm{mmHg}$, it was appreciably lower in monkeys $(2.5+/-0.8 \mathrm{mmHg})$. The author suggested this may be the case for a variety of reasons including reduced blinking rates in rabbits (hence less clearance of Y-39983), and a difference in the inter and intra-species expression of ROCK or its 
substrates, suggesting that in clinical administration individuals may have varying responses [119]. The following year, Tanihara et al used various concentrations of ophthalmic solution of Y-39983 in a randomised, double blind, phase one trial in humans [83]; It was elucidated that the once daily $0.1 \%$ group had an IOP reduction of $3 \mathrm{mmHg}$ at four hours.

Nakajima et al performed PCR analysis in both monkeys and humans, revealing that in both species greater levels of mRNAs for ROCK and ROCK substrates can be found in the TM compared to $\mathrm{CM}$, although this $\mathrm{TM}$ versus $\mathrm{CM}$ discrepancy was not as high in humans as it was in monkeys [84]. As a result, the over-riding effect of Y-39883 led to relaxation of TM in monkey compared to modest relaxation in $\mathrm{CM}$, suggesting that TM was the principle site for regulating IOP by manipulation of the ROCK-signalling pathway. This subverts the previously mentioned side-effects commonly encountered with pilocarpine, namely changes in accommodation and meiosis [84].

Some reports have described a topical formulation of AR-12286 that has more selectivity for ROCK inhibition than Y-39983. A topical preparation of AR-12286 applied to non-human primates reduced IOP in normotensives by increasing trabecular outflow [85]. Whilst phase two studies revealed maximum reduction of $28 \%$ noted in twice daily $0.25 \%$ AR-12286 application, the long-term tolerability profile and reduction of IOP in humans is not known[85]. In fact, phase two studies have been undertaken successfully for K-115 [86] , Y39983 [83], INS-117548 and RKI-983, with the latter shown to be inferior to, and causing more adverse events in comparison to latanoprost (IOP lowering of 4.8 versus $6.7 \mathrm{mmHg}$ at day 29) [87]. 


\section{Renin-angiotensin system (RAS):}

Aside from ROCK related signalling cascades, the renin-angiotensin system (RAS) pathway exerts an important role in IOP control. Ocular blood flow depends on both perfusion pressure (mean arterial blood pressure) and resistance to flow, determined by the vascular calibre of the arterioles and capillaries, which can be influenced by dilators and constrictors such as RAS [120]. Evidence has accrued that local RAS exists in the human eye and that systemic anti-hypertensive drugs can act on the ocular RAS pathway to reduce the IOP [99]. For example, topical olmesartan in cynomolgus monkeys given twice daily reduced IOP by $6.9 \mathrm{mmHg}$ at day 5 [121]. Other examples in the literature include publications demonstrating that intra-cameral administration of Angiotensin II diminishes uveoscleral out-flow in anaesthetised cats [94], and oral ACE-inhibitor (ACE-I) and angiotensin receptor blocker Losartan causes reduced IOP in human subjects [100]. Moreover, angiotensin receptor blockers have also been demonstrated to be neuroprotective against ganglion cell loss in a rat chronic glaucoma model [95]. Many RAS components have been shown in cultured human ciliary body cells (CB) and TM cells [96], hence affecting both production and outflow. Similar to systemic processing, local angiotensin can be catalysed by enzymes other than angiotensin converting enzyme-one (ACE1), including chymase or cathepsin G [97]. Unlike systemic RAS, there is a more integral role for the enzyme ACE2 and its product angiotensin, which has been shown to activate the Mas receptor and act opposite to angiotensin II by increasing outflow and reducing IOP [98]. Vaajanen et al noted the expression of this novel angiotensin receptor Mas in the $C B$ and retina, with ACE2 present in ocular structures [99]. ACE-Is act to activate the nitric oxide (NO) pathway and reduce the formation of the vasoconstrictive peptide endothelin-1 (ET-1) [99]. Other potential agents 
that could be putative therapeutic targets include compounds that increase ACE2, and hence increase production of Ang and Mas receptor agonists.

\section{Endothelin-1 (ET-1) Pathway:}

As alluded to above, the homeostasis achieved by the balance between ET-1 and NO is important in the pathogenesis of glaucoma. ET-1 has been postulated as an important player as it has the combined role of inducing $\mathrm{ON}$ ischaemia through vasoconstriction, and glial cell proliferation [122], as well as by contributing to congestion of aqueous egress through the TM [123]. It is a twenty-one amino-acid peptide, produced by cleavage from preproendothelin through converting enzymes. ET-1 is naturally present in the eye, produced by non-pigmented ciliary epithelium. Choritz et al performed a small study looking at ET-1 in the aqueous humour of 35 humans eyes with POAG, and 21 eyes with pseudoexfoliation glaucoma (PXFG) [124]; They showed that aqueous humour ET-1 was significantly elevated in glaucomatous eyes in comparison to controls, while there was no correlation between plasma ET-1 with that found in aqueous humour. Renieri et al proposed that calcium independent signalling is an important cascade mediated by ET-1 [88]; In a bovine population, the authors created a calcium independent environment by administrating the buffers EGTA and BAPTA-AM. Subsequent application of the ET-1 receptor antagonists $\mathrm{BQ} 123$ significantly reduced the contraction of smooth muscles in the TM [88]. Interestingly, ET-1-induced contraction was abolished in the presence of Y-39983, suggesting that the ET-1 pathway leading to muscle contraction is independent of $\mathrm{Ca}$, but reliant on the ROCK signalling cascade. Whilst both ET-A and ET-B receptors are involved, the former was associated with a greater affect on contractile force [88]. 
As well as being a vasoconstrictive peptide, ET-1 also acts as an anti-apoptotic agent. Ehrenreich et al showed that when exerting its affect via the ET-B receptor, ET1 is associated with neuronal survival in the brain [89]. A cerebrovascular accident model revealed that phospholipase A2 is expressed in the cerebral cortex and its activation causes an intracellular influx of calcium to mediate neuronal cell death. The authors postulated correctly that the ET-B receptor agonist ET3 administration would inhibit the phospholipase A2 signalling cell death mechanisms. Furthermore, blockers of L-type voltage-dependent calcium channel (L-VSCC), not only suppressed the calcium influx, but also exhibited neuroprotective effects [90].

Incidentally, Yagami et al 2002 showed that the phospholipase A2 liberated in any cerebral ischaemic insult causes cell death in a dose-dependent manner above 0.1 micrometer, predominantly by the apoptotic pathways [91]. The author aimed to assess this putative role in toxicity by inducing middle cerebral artery occlusion in rat models and subsequent evaluation of cortical neurons. It was shown that the phospholipase A2 inhibitor indoxam not only negated the toxicity effect of phospholipase $A 2$, but it also reduced the overall neurodegeneration in the cortex [91].

\section{Nitric Oxide (NO):}

The situation is not as simple as pure interplay between the vasoconstrictor ET1 and the vasodilator NO, as in the presence of certain environments the latter can act as a source of reactive oxygen species and lead to lipid peroxidation. Hence, the exact role that NO plays after neural injury and in the pathogenesis of glaucoma per se is controversial, with studies being contradictory regarding its role as either protective or destructive. It is likely that the 
exact role it exhibits depends on the environment it is exposed to and the nature of the upregulating enzymes. For instance, Nathanson et al showed that immunological analysis of the outflow pathway revealed an abundance of NOS-3 receptors, which typically are found in human vascular endothelium rather than cerebral tissue [101]. Further biochemical analysis confirmed NADPH led production of NO, concentrated at sites of outflow, specifically the longitudinal fibers in the CM, TM, and Schlemm's canal [101]. Conversely, Garcia et al 2012 administered neural-derived peptides Cop-1 and A91, liberating T-cells activated to Th2-type immune response, capable of counteracting NO production [102]. This was seen when glial cells were cultured with these activated T-cells in vitro, leading to the reduced production of NO. Furthermore, the iNOS mRNA expression significantly diminished, iNOS being the most important enzyme in NO synthesis after neuronal injury [102].

\section{Adenosine agonists and cannabinoids:}

There are many other mediators that could potentially play a pivotal role in the aetiology of glaucoma, and numerous potential pathways that could be manipulated in glaucoma management. The endogenous purine analogue adenosine acts via four different receptor types, with Zhang et al showing that RGC's express predominantly the A3 variant [92]. Currently, trials are on-going with the following mediators: INO-8875/PJ-875 (A1 agonist), OPA-6566 (A2A agonist), ATL-313 (A2A agonist) and CF-101 (A3 agonist), with Galvao et al recently publishing that the CF-101 decreased the number of apoptotic RGCs, thereby increasing RGC survival in a rat models of cell degeneration induced by excitotoxicity [93]. The authors do however caution the effect of CF-101 may be different both in varying experimental models and concentrations used [93]. 
It is known that G-protein coupled activation of $\mathrm{CB} 1$ and $\mathrm{CB} 2$ receptors through tetrahydrocannabinol can reduce IOP [125]. The evidence is conflicting as to whether pursuing this as a clinical modality is a worthwhile venture; A study by Novartis in 2007 revealed that it's effect was equivalent to placebo and the company had no plans to take the research further [126]. Conversely, a study by Chien et al revealed that twice daily administration in cynomolgus monkeys led to a reduction in IOP of $3.4 \mathrm{mmHg}$ [127]. 


\section{Glaucoma as a neurodegenerative disease: Apoptosis}

Comparisons are often drawn between glaucoma and a host of other neurodegenerative diseases. Of these conditions, similarities found between glaucoma and Alzheimer's disease (AD) are among the more frequently cited. Like AD, glaucoma has an increased incidence with age, being progressive in nature [128]. There is also evidence to suggest comorbidities with the co-incidence of AD and glaucoma [129,130], although this is controversial [131].

Neuronal cell death is the hallmark feature in all neurodegenerative diseases such as glaucoma and AD. In glaucoma, visual loss is due to RGC death via apoptosis, and therefore RGC apoptosis needs to be curbed in order for progression of this neurodegenerative disease to be halted. In AD, neuronal cell death in the cerebral cortex is caused by the triad of accumulation of extracellular beta-amyloid protein, increase in intracellular tau protein, and neurofibrillary tangles [131]. Some studies have alluded a parallel molecular basis of RGC death in glaucoma; caspases are heterodimers that are central in neuronal cell death, through mechanisms which include cleavage of structural elements, and degrading DNA repair enzymes [132]. Amyloid precursor protein (APP), which is vital for homeostasis of the synaptic junction in neurons, contains a cleavage site for the protein caspase-3. McKinnon et al showed that in rat models of glaucoma, caspase- 3 mRNA and caspase- 3 mediated APP cleavage product was increased in comparison to controls [103]. The cleavage product in turn acts to up-regulate amyloid beta, which is the major constitute of senile plaques in Alzheimer's disease, but is also postulated to be contributory to the neurodegenerative disease glaucoma [103]. Guo et al revealed that amyloid beta $(A \beta)$ is elevated in experimental glaucoma models, and that exogenous administration of $A \beta$ induces RGC 
apoptosis [104]. The authors hypothesized interventions that target $A \beta$ might reduce the levels of RGC apoptosis and tested the administration of a $\beta$-secretase inhibitor (which blocks initial step of APP cleavage in the amyloidgenic pathway), CR (which blocks A $\beta$ aggregation and toxicity) and $A \beta a b$ (which increase $A \beta$ clearance); they noted that compared with $A \beta a b$ single therapy, triple therapy was far more effective in the mean reduction of RGC apoptosis (74\% versus $84 \%$ respectively) [104].

When a cell is severely stressed, apoptosis is induced by the endoplasmic reticulum (ER) stress pathway. This is mediated by factors including C/EBP homologous protein (CHOP) $[133,134]$. Doh et al studied ER stress, the CHOP pathway, and glaucoma using the chronic injury model, inducing glaucoma in rats by cauterizing the episcleral veins; It was shown that chronically raised IOP up-regulated the PERK/CHOP pathway inducing apoptosis (PERK being expressed one-week post induction of glaucoma, and CHOP peaking at 4 weeks) [105].

Protein mis-folding is thought to be the common underlying key feature shared by $A D$ and pseudoexoliation glaucoma; In $A D$, the soluble amyloid-beta protein is transformed to harmful fibrillar amyloid-beta plaques by what is thought to be a mis-folding mechanism. In psudoexfoliation glaucoma, abnormal fibrillar extracellular material deposits are found in ocular structures and systemic tissues [135]. These deposits cause secondary glaucoma by increasing resistance to aqueous outflow via the trabeceular meshwork pathway. Analysis of these exfoliation materials has revealed a complex abnormal metabolism of glycosaminoglycans, non-collagenous basement membrane components, and epitopes of the elastic fibre system such as fibrillium $[136,137]$. The heavily cross-linked nature of these proteins, and their assembly in to a supra-molecular fibrillar structure implies an underlying 
mis-folding mechanism similar to that seen in AD [131]. Misfolded amyloid-beta is also found surrounding RGCs in POAG, likely as a result of cellular stress [131].

A caveat from the preceding section is that whilst apoptosis is an important causative factor $\underline{\text { for vision loss in glaucoma, other independent axonal degeneration mechanisms also exist. }}$ Perhaps the most eloquent paper depicting this is Libby et al 2005 using BAX (a proapoptotic gene) knock out mice [138]; The authors elegantly demonstrated that while BAX deficiency protected RGCs from apoptosis in an inherited glaucoma model, it did not prevent axonal degeneration, leading the authors to conclude that distinct somal and axonal degeneration pathways are at play in this model of glaucoma [138]. These findings highlight the importance of a quest for treatment modalities that also target axonal degeneration.

$\underline{\text { Immune-modulation \& oxidative stress }}$

In the physiological neuronal environment, the innate immune system serves to provide immunity against pathogens and remove dying host cells, thereby minimising inflammation and reducing the risk of developing autoimmunity [139]. The classic complement system is initiated by C1q [140]. In chronic neurodegenerative conditions however, there is an upregulation of pro-inflammatory cytokines, which act to propagate the immune response and thus lead to sustained neurotoxicity [106]. Tezel et al demonstrated this phenomenon in glaucoma by finding the up-regulation of complement factors and down-regulation of their inhibitors in glaucomatous RGC's using proteomic analyses [107]. 
In experimental glaucoma, RGC's undergo accelerated apoptosis by activation of the classical complement system, and Ding et al determined that this could be achieved without the need of immunoglobulins (Ig), with the complement cascade initiating RGC damage by C1q binding to other ligands such as $\alpha 2 \beta 1$ integrin [108]. A mouse model genetically devoid of the ability to rearrange and recombine Ig and T-cell receptors, was subjected to raised IOP, and found to have no difference in loss of RGC's compared to control models subjected to raised IOP at 28 days [108]. Howell et al used DBA/2J mice, a widely used mouse model of glaucoma, and demonstrated that combined blockade of the endothelin and classical complement pathway, by administrating Bosentan (dual ET-A and ET-B receptor antagonist) led to significantly more RGC survival than blockade of one pathway alone [109].

Increasing evidence is accumulating that oxidative stress and mitochondrial dysfunction have roles in neurodegenerative disease, including RGC apoptosis. Whilst the exact mechanism are not certain, it is likely that reactive oxygen species (ROS) are central in causing cellular damage $[112,141]$. In essence, if ROS production exceeds the anti-oxidant capacity of the mitochondria, RGCs are likely to activate the apoptotic pathways. Ju et al used electron microscopy analyses in glaucomatous $\mathrm{ONH}$, to demonstrate IOP induced mitochondrial changes including fission, matrix swelling and abnormal cristae depletion [111]. It is therefore logical that the mitochondria are effective therapeutic targets to reduce oxidative stress on the cell in a bid to reduce RGC apoptosis. Tezel et showed that reducing ROS generation could protect RGC's from apoptosis [142], while a host of in vivo studies have demonstrated that the anti-oxidant SS-31 has the capacity to reduce oxidative damage and indeed promoted anti-apoptotic protein expression [113-115]. The need for 
these specific inhibitors is due to the fact that systemic anti-oxidants like vitamin $\mathrm{E}$ and $\mathrm{C}$ lack the ability to cross the blood-retina and blood-brain barriers.

Some groups have hypothesised that glaucoma is primarily due to compromised blood supply to the optic nerve head, resulting in mitochondrial energy supplies not being met in such an ischaemic environment. The mitochondria adapt by suppressing the energy sensitive cellular processes, predominantly by inhibiting mTORC1 $[143,144]$. Many potential stimuli have been implicated in the aetiology of RGC apoptosis in glaucoma. Cultured retinal cells exposed to short wave-length blue light undergo apoptosis, with the up-regulation of REDD1 causing the dysfunction. Del Olmo-Aguado et al showed that inhibiting the affect of REDD1 with rapamycin ameliorated cell death [145], a finding confirmed in vivo by Kitaoka et al who used intra-vitreal injections of rapamycin in a rat model to reduced optic nerve degeneration [146].

A variety of toxic materials liberated locally from cells such as astrocytes, can lead to the inability of mitochondria to maintain normal function [110]. Co-culture of RGC's and glial cells showed that TNF- $\alpha$ is secreted by stressed glial cells, leading to apoptotic death of RGCs [147], while homocysteine release leads to RGC loss secondary to dysregulation of mitochondria [148]. It therefore stands to reason that potential interventions targeting mitochondrial protection could have great clinical implications; these could include spectral filters on spectacles to prevent photo-toxicity, or suppression of oxidative stress, for instance by superoxide dismutase (SOD2) gene delivery [149]. 


\section{Stem cell therapy:}

Glaucoma clinics are full of optimistic patients expressing hope for new scientific breakthroughs that can relate to clinical practice and at the cornerstone of this is always a conversation about prevention of progression and advances in regeneration, namely stem cell therapy.

Several groups have shown that impaired retrograde transport of neurotrophic factors at the level of the optic nerve is important in the aetiology of glaucoma, and it is thought that stem cell transplantation can ameliorate neurodegenerative conditions in the CNS, partly due to neurotrophic factor secretion $[150,151]$. Schori et al have shown that autoimmune Tcells directed against CNS associated myelin antigens protect neurons from secondary degeneration. This paper advocated the passive and active immunization against copolymer (Cop-1), as a substitute for natural myelin Ag, for neuroprotection in optic nerve pathology simulated in mice by the intra-vitreal injection of glutamate [152]; The number of surviving RGCs in the group immunized 10 days prior with emulsified Cop-1 was far higher than controls. This pattern was observed even if the immunization was on the day of glutamate insult, but no longer seen if immunisation occurred two weeks after the insult. This reduction in loss of RGC was independent of effects on IOP [152]. Johnson et al looked at intra-vitreal delivery of local or systemic femur bone marrow-derived mesenchymal stem cells (MSC) into a rat model of laser-induced glaucoma [153]; They showed that this technique of administration ensured that the majority of cells remained within the vitreous cavity, whilst a small number migrated within the nerve fibre layer. Although the primary outcome measure was ON damage, and the survival of RGC bodies was not directly investigated, the results were statistically significant for RGC axon survival, which was lost 
when the delivery method was intra-venous [153]. Excitingly, Ng et al are currently undertaking a clinical trial delivering bone marrow derived cells in Florida [154].

\section{Neuronal regeneration:}

Sadly, inherent to neurological cells is their lack of ability to repair and regenerate in response to insults. Although in their natural habitat RGC's lack the propensity to regrow injured axons, various authors have begun to describe the process of regeneration and offered hope to facilitate this process. Indeed, Jo et al (1998) showed that injured mammalian RGCs exposed in culture to the molecular micro-environment of the peripheral nervous system, leads to regenerated growth [155]. Whilst many neurotrophic agents have been suggested, the only proven molecules to be described are ciliary neurotrophic factor (CNTF) and leukaemia inhibitory factor (LIF), both leading to the up-regulation of a marker for high axon regeneration growth associated protein 43 (GAP-43), confirmed by Western blots [156]. GAP-43 is usually undetectable in physiological conditions, but is strongly up regulated in conditions of damage and subsequent attempts to regenerate. Cultivating RGCs with CNTF and LIF led to increasing the percentage of cells with axons greater than five cell diameters fivefold over controls, with the effect being more dramatic the longer the cells were cultured [156].

Whilst not yet at the clinical trial stages, nerve growth factor (NGF) is generating a growing amount of interest. The premise for its use in glaucoma stems from encouraging results seen following its intra-cerebral application in patients with Alzheimer's and Parkinson's diseases $[157,158]$. Lambiase et al administered intra-vitreal NGF in a rat glaucoma model, leading to lower anti-TUNEL staining, as a marker of apoptotic cell death, and higher Bcl- 
2/Bax ratio in the treatment arm, both indicating greater RGC survival [159]. In the same paper, the group also reported that topical murine NGF $200 \mu \mathrm{g} / \mathrm{mL}$ given to human patients with advanced glaucomatous optic neuropathy led to sustained improvements in neuronal function after three months, as demonstrated by electrophysiological tests [159].

Other neurotropic factors with as yet no proven evidence of inducing neuro-regeneration include BDNF, neurotrophin-3 \& 4 (NT3, NT4), insulin-like growth factor (IGF), basic fibroblast growth factor (bFGF) and neuregulins. Many authors have studied the specific neurite growth inhibitors myelin associated glycoprotein (MAG), Nogo-A, and Omgp, which exert their effects on the common receptor Nogo-receptor (NgR) [160-162]; Su et al induced optic nerve crush injury in NgR knock-out mice and elucidated that GAP-43 was highly expressed, when compared to control subjects. Fischer et al showed that once activated by macrophage-derived factors, $R G C^{\prime} s$ can regenerate their axons for vast distances through the distal optic nerve [163]; The authors administered RGC's in-vitro with a truncated dominant negative form of $\mathrm{NgR}$ via an adeno-virus vector and noted a fortnight after the induced injury, the dominant negative group had seventy-five times more axons extending more than one millimetre beyond the site of injury compared to controls expressing NR $(n=5)$ [163], suggesting that $N g R$ antagonists are putative therapeutic targets. 


\section{Conclusions and future perspective:}

Glaucoma is a complex neurodegenerative process with a large number of mediators eliciting key roles in its pathogenesis. While a plethora of medical and surgical treatments currently address the only modifiable risk factor, IOP, there is still a subset of patients whose disease inevitably progresses despite treatment.

The neuroprotective and neuroregenerative agents discussed here, some of which are already commercially available, may take the management of glaucoma to a new direction and complement the currently established IOP based treatment paradigm. This may also impact the way we manage glaucoma at the clinical practice level, as the focus will move beyond merely IOP control. Other measurement parameters such as electrophysiology, visual field testing, as well as retinal and neuroimaging may become increasingly important in the monitoring and management of the disease as our treatment modalities aim to address more than just IOP in the future. 


\section{Financial \& competing interests disclosure}

MF Cordeiro is an inventor on patent applications owned by UCL and pertaining to

Detection of Apoptozing Retinal Cells. The authors have no other relevant affiliations or

financial involvement with any organisation or entity with a financial interest in or financial

conflict with the subject matter or materials discussed in the manuscript apart from those

disclosed.

No writing assistance was utilized in the production of this manuscript. 


\section{References:}

1. Cook C, Foster P. Epidemiology of glaucoma: what's new? Can. J. Ophthalmol. 47(3), 223-6 (2012).

2. Morgan JE. Retina ganglion cell degeneration in glaucoma: an opportunity missed? A review. Clin. Experiment. Ophthalmol. 40(4), 364-8.

3. Almasieh M, Wilson AM, Morquette B, Cueva Vargas JL, Di Polo A. The molecular basis of retinal ganglion cell death in glaucoma. Prog. Retin. Eye Res. 31(2), 152-81 (2012).

4. Schwartz M, Yoles E. Neuroprotection: a new treatment modality for glaucoma? Curr. Opin. Ophthalmol. 11(2), 107-11 (2000).

5. Arend KO, Redbrake C. [Update on prospective glaucoma intervention studies]. Klin. Monbl. Augenheilkd. 222(10), 807-13 (2005).

6. Brubaker RF. Delayed functional loss in glaucoma. LII Edward Jackson Memorial Lecture. Am. J. Ophthalmol. 121(5), 473-83 (1996).

7. Gupta N, Ang L-C, Noël de Tilly L, Bidaisee L, Yücel YH. Human glaucoma and neural degeneration in intracranial optic nerve, lateral geniculate nucleus, and visual cortex. Br. J. Ophthalmol. 90(6), 674-8 (2006).

8. Chaturvedi N, Hedley-Whyte ET, Dreyer EB. Lateral geniculate nucleus in glaucoma. Am. J. Ophthalmol. 116(2), 182-8 (1993).

9. Davis BM, Crawley L, Pahlitzsch M, Javaid F, Cordeiro MF. Glaucoma: the retina and beyond. Acta Neuropathol. (2016).

10. Wang J, Li T, Sabel BA, et al. Structural brain alterations in primary open angle glaucoma: a 3T MRI study. Sci. Rep. 6, 18969 (2016).

11. Zhang YQ, Li J, Xu L, et al. Anterior visual pathway assessment by magnetic resonance 
imaging in normal-pressure glaucoma. Acta Ophthalmol. 90(4), e295-302 (2012).

12. Li C, Cai P, Shi L, et al. Voxel-based morphometry of the visual-related cortex in primary open angle glaucoma. Curr. Eye Res. 37(9), 794-802 (2012).

13. Quaranta L, Turano R, Pizzolante T. Levobetaxolol hydrochloride: a review of its pharmacology and use in the treatment of chronic open-angle glaucoma and ocular hypertension. Clin. Ophthalmol. 1(2), 93-7 (2007).

14. Seki M, Tanaka T, Matsuda $\mathrm{H}$, et al. Topically administered timolol and dorzolamide reduce intraocular pressure and protect retinal ganglion cells in a rat experimental glaucoma model. Br. J. Ophthalmol. 89(4), 504-7 (2005).

15. Wood JP, DeSantis L, Chao HM, Osborne NN. Topically applied betaxolol attenuates ischaemia-induced effects to the rat retina and stimulates BDNF mRNA. Exp. Eye Res. 72(1), 79-86 (2001).

16. Tamaki Y, Araie M, Tomita K, Nagahara M. Effect of topical betaxolol on tissue circulation in the human optic nerve head. J. Ocul. Pharmacol. Ther. 15(4), 313-21 (1999).

17. NICE. Glaucoma: diagnosis and management [Internet]. Available from: nice.org.uk/guidance/cg85.

18. Toris CB, Gabelt BT, Kaufman PL. Update on the mechanism of action of topical prostaglandins for intraocular pressure reduction. Surv. Ophthalmol. 53 Suppl1, S10720 (2008)

19. Brubaker RF, Schoff EO, Nau CB, Carpenter SP, Chen K, Vandenburgh AM. Effects of AGN 192024, a new ocular hypotensive agent, on aqueous dynamics. Am. J. Ophthalmol. 131(1), 19-24 (2001).

20. Christiansen GA, Nau CB, McLaren JW, Johnson DH. Mechanism of ocular hypotensive 
action of bimatoprost (Lumigan) in patients with ocular hypertension or glaucoma. Ophthalmology. 111(9), 1658-62 (2004).

21. Dinslage S, Hueber A, Diestelhorst M, Krieglstein G. The influence of Latanoprost $0.005 \%$ on aqueous humor flow and outflow facility in glaucoma patients: a doublemasked placebo-controlled clinical study. Graefes Arch. Clin. Exp. Ophthalmol. 242(8), $654-60$ (2004).

22. Toris CB, Zhan G, Fan S, et al. Effects of travoprost on aqueous humor dynamics in patients with elevated intraocular pressure. J. Glaucoma. 16(2), 189-95 (2007).

23. Kanamori A, Naka M, Fukuda M, Nakamura M, Negi A. Latanoprost protects rat retinal ganglion cells from apoptosis in vitro and in vivo. Exp. Eye Res. 88(3), 535-41 (2009).

24. Kudo H, Nakazawa $T$, Shimura $M$, et al. Neuroprotective effect of latanoprost on rat retinal ganglion cells. Graefes Arch. Clin. Exp. Ophthalmol. 244(8), 1003-9 (2006).

25. Kanamori A, Naka M, Fukuda M, Nakamura M, Negi A. Tafluprost protects rat retinal ganglion cells from apoptosis in vitro and in vivo. Graefes Arch. Clin. Exp. Ophthalmol. 247(10), 1353-60 (2009).

26. Sugrue MF. Pharmacological and ocular hypotensive properties of topical carbonic anhydrase inhibitors. Prog. Retin. Eye Res. 19(1), 87-112 (2000).

27. Harris A, Arend O, Arend S, Martin B. Effects of topical dorzolamide on retinal and retrobulbar hemodynamics. Acta Ophthalmol. Scand. 74(6), 569-72 (1996).

28. Martínez A, Sánchez-Salorio M. A comparison of the long-term effects of dorzolamide $2 \%$ and brinzolamide $1 \%$, each added to timolol $0.5 \%$, on retrobulbar hemodynamics and intraocular pressure in open-angle glaucoma patients. J. Ocul. Pharmacol. Ther. 25(3), 239-48 (2009). 
29. Rankin SJ. Color Doppler imaging of the retrobulbar circulation in glaucoma. Surv. Ophthalmol. 43 Suppl 1, S176-82 (1999).

30. Adkins JC, Balfour JA. Brimonidine. A review of its pharmacological properties and clinical potential in the management of open-angle glaucoma and ocular hypertension. Drugs Aging. 12(3), 225-41 (1998).

31. Matsuo T, Cynader MS. Localization of alpha-2 adrenergic receptors in the human eye. Ophthalmic Res. 24(4), 213-9 (1992).

32. Woldemussie $\mathrm{E}$, Wijono $\mathrm{M}$, Pow D. Localization of alpha 2 receptors in ocular tissues. Vis. Neurosci. 24(5), 745-56.

33. Krupin T, Liebmann JM, Greenfield DS, Ritch R, Gardiner S, Low-Pressure Glaucoma Study Group. A randomized trial of brimonidine versus timolol in preserving visual function: results from the Low-Pressure Glaucoma Treatment Study. Am. J. Ophthalmol. 151(4), 671-81 (2011).

34. Cordeiro MF, Levin LA. Clinical Evidence for Neuroprotection in Glaucoma. Am. J. Ophthalmol. 152(5), 715-716 (2011).

35. Galindo-Romero C, Harun-Or-Rashid M, Jiménez-López M, Vidal-Sanz M, AgudoBarriuso M, Hallböök F. Neuroprotection by $\alpha 2$-Adrenergic Receptor Stimulation after Excitotoxic Retinal Injury: A Study of the Total Population of Retinal Ganglion Cells and Their Distribution in the Chicken Retina. PLoS One. 11(9), e0161862 (2016).

36. Lafuente MP, Villegas-Pérez MP, Sobrado-Calvo P, García-Avilés A, Miralles de Imperial J, Vidal-Sanz M. Neuroprotective effects of alpha(2)-selective adrenergic agonists against ischemia-induced retinal ganglion cell death. Invest. Ophthalmol. Vis. Sci. 42(9), 2074-84 (2001).

37. Nizari S, Guo L, Davis BM, et al. Non-amyloidogenic effects of $\alpha 2$ adrenergic agonists: 
implications for brimonidine-mediated neuroprotection. Cell Death Dis. 7(12), e2514 (2016).

38. Dong C-J, Guo Y, Agey P, Wheeler L, Hare WA. Alpha2 adrenergic modulation of NMDA receptor function as a major mechanism of RGC protection in experimental glaucoma and retinal excitotoxicity. Invest. Ophthalmol. Vis. Sci. 49(10), 4515-22 (2008).

39. Gao H, Qiao X, Cantor LB, WuDunn D. Up-regulation of brain-derived neurotrophic factor expression by brimonidine in rat retinal ganglion cells. Arch. Ophthalmol. (Chicago, III. 1960). 120(6), 797-803 (2002).

40. Wheeler LA, Lai R, Woldemussie E. From the lab to the clinic: activation of an alpha-2 agonist pathway is neuroprotective in models of retinal and optic nerve injury. Eur. J. Ophthalmol. 9 Suppl 1, S17-21.

41. Yiğit U, Erdenöz S, Uslu U, et al. An immunohistochemical analysis of the neuroprotective effects of memantine, hyperbaric oxygen therapy, and brimonidine after acute ischemia reperfusion injury. Mol. Vis. 17, 1024-33 (2011).

42. Lambert WS, Ruiz L, Crish SD, Wheeler LA, Calkins DJ. Brimonidine prevents axonal and somatic degeneration of retinal ganglion cell neurons. Mol. Neurodegener. 6(1), 4 (2011).

43. Crish SD, Sappington RM, Inman DM, Horner PJ, Calkins DJ. Distal axonopathy with structural persistence in glaucomatous neurodegeneration. Proc. Natl. Acad. Sci. U. S. A. 107(11), 5196-201 (2010).

44. Buckingham BP, Inman DM, Lambert $\mathrm{W}$, et al. Progressive ganglion cell degeneration precedes neuronal loss in a mouse model of glaucoma. J. Neurosci. 28(11), 2735-44 (2008). 
45. Beal MF. Coenzyme Q10 administration and its potential for treatment of neurodegenerative diseases. Biofactors. 9(2-4), 261-6 (1999).

46. Papucci L, Schiavone N, Witort E, et al. Coenzyme q10 prevents apoptosis by inhibiting mitochondrial depolarization independently of its free radical scavenging property. J. Biol. Chem. 278(30), 28220-8 (2003).

47. Kroemer G, Reed JC. Mitochondrial control of cell death. Nat. Med. 6(5), 513-9 (2000).

48. Russo R, Cavaliere F, Rombolà L, et al. Rational basis for the development of coenzyme Q10 as a neurotherapeutic agent for retinal protection. Prog. Brain Res. 173(8), 575-582 (2008).

49. Nucci C, Tartaglione R, Cerulli A, et al. Retinal damage caused by high intraocular pressure-induced transient ischemia is prevented by coenzyme Q10 in rat. Int. Rev. Neurobiol. 82, 397-406 (2007).

50. Lee D, Kim K-Y, Shim MS, et al. Coenzyme Q10 ameliorates oxidative stress and prevents mitochondrial alteration in ischemic retinal injury. Apoptosis. 19(4), 603-14 (2014).

51. Lee D, Shim MS, Kim K-Y, et al. Coenzyme Q10 inhibits glutamate excitotoxicity and oxidative stress-mediated mitochondrial alteration in a mouse model of glaucoma. Invest. Ophthalmol. Vis. Sci. 55(2), 993-1005 (2014).

52. Parisi V, Centofanti M, Gandolfi S, et al. Effects of coenzyme Q10 in conjunction with vitamin E on retinal-evoked and cortical-evoked responses in patients with openangle glaucoma. J. Glaucoma. 23(6), 391-404 (2014).

53. Secades JJ. Citicoline: pharmacological and clinical review, 2010 update. Rev. Neurol. 52 Suppl 2, S1-S62 (2011). 
54. Parisi V, Manni G, Colacino G, Bucci MG. Cytidine-5'-diphosphocholine (citicoline) improves retinal and cortical responses in patients with glaucoma. Ophthalmology. 106(6), 1126-34 (1999).

55. Matteucci A, Varano M, Gaddini L, et al. Neuroprotective effects of citicoline in in vitro models of retinal neurodegeneration. Int. J. Mol. Sci. 15(4), 6286-97 (2014).

56. Oshitari T, Fujimoto N, Adachi-Usami E. Citicoline has a protective effect on damaged retinal ganglion cells in mouse culture retina. Neuroreport. 13(16), 2109-11 (2002).

57. Secades JJ, Alvarez-Sabín J, Castillo J, et al. Citicoline for Acute Ischemic Stroke: A Systematic Review and Formal Meta-analysis of Randomized, Double-Blind, and Placebo-Controlled Trials. J. Stroke Cerebrovasc. Dis. 25(8), 1984-96 (2016).

58. Hazama T, Hasegawa T, Ueda S, Sakuma A. Evaluation of the effect of CDP-choline on poststroke hemiplegia employing a double-blind controlled trial. Assessed by a new rating scale for recovery in hemiplegia. Int. J. Neurosci. 11(3), 211-25 (1980).

59. Agnoli A, Ruggieri S, Denaro A, Bruno G. New strategies in the management of Parkinson's disease: a biological approach using a phospholipid precursor (CDPcholine). Neuropsychobiology. 8(6), 289-96 (1982).

60. Parisi V, Centofanti M, Ziccardi L, et al. Treatment with citicoline eye drops enhances retinal function and neural conduction along the visual pathways in open angle glaucoma. Graefes Arch. Clin. Exp. Ophthalmol. 253(8), 1327-40 (2015).

61. Parisi V, Coppola G, Centofanti M, et al. Evidence of the neuroprotective role of citicoline in glaucoma patients. Prog. Brain Res. 173, 541-54 (2008).

62. Parisi V, Ziccardi L, Roberti G, Tanga L, Manni G. Commentary: Citicoline: A Food Beneficial for Patients Suffering from or Threated with Glaucoma. Front. Aging Neurosci. 8, 194 (2016). 
63. Ottobelli L, Manni GL, Centofanti M, lester M, Allevena F, Rossetti L. Citicoline Oral Solution in Glaucoma: Is There a Role in Slowing Disease Progression? Ophthalmologica. 229(4), 219-226 (2013).

64. Rejdak R, Toczołowski J, Kurkowski J, et al. Oral citicoline treatment improves visual pathway function in glaucoma. Med. Sci. Monit. 9(3), PI24-8 (2003).

65. Parsons CG, Stöffler A, Danysz W. Memantine: a NMDA receptor antagonist that improves memory by restoration of homeostasis in the glutamatergic system--too little activation is bad, too much is even worse. Neuropharmacology. 53(6), 699-723 (2007).

66. WoldeMussie E, Yoles E, Schwartz M, Ruiz G, Wheeler LA. Neuroprotective effect of memantine in different retinal injury models in rats. J. Glaucoma. 11(6), 474-80 (2002).

67. Celiker H, Yuksel N, Solakoglu S, Karabas L, Aktar F, Caglar Y. Neuroprotective Effects of Memantine in the Retina of Glaucomatous Rats: An Electron Microscopic Study. J. Ophthalmic Vis. Res. 11(2), 174-82.

68. Lipton SA. Possible role for memantine in protecting retinal ganglion cells from glaucomatous damage. Surv. Ophthalmol. 48 Suppl 1, S38-46 (2003).

69. Girkin CA. Strategies for neuroprotection. J. Glaucoma. 10(5 Suppl 1), S78-80 (2001).

70. Honjo M, Tanihara $\mathrm{H}$, Inatani $\mathrm{M}$, et al. Effects of rho-associated protein kinase inhibitor Y-27632 on intraocular pressure and outflow facility. Invest. Ophthalmol. Vis. Sci. 42(1), 137-44 (2001).

71. Rao P V, Deng PF, Kumar J, Epstein DL. Modulation of aqueous humor outflow facility by the Rho kinase-specific inhibitor Y-27632. Invest. Ophthalmol. Vis. Sci. 42(5), 102937 (2001). 
72. Delaney $Y$, Walshe TE, O'Brien C. Vasospasm in glaucoma: clinical and laboratory aspects. Optom. Vis. Sci. 83(7), 406-14 (2006).

73. Grieshaber MC, Flammer J. Blood flow in glaucoma. Curr. Opin. Ophthalmol. 16(2), 79-83 (2005).

74. Kandabashi T, Shimokawa H, Miyata K, et al. Evidence for protein kinase C-mediated activation of Rho-kinase in a porcine model of coronary artery spasm. Arterioscler. Thromb. Vasc. Biol. 23(12), 2209-14 (2003).

75. Chrissobolis S, Budzyn K, Marley PD, Sobey CG. Evidence that estrogen suppresses rho-kinase function in the cerebral circulation in vivo. Stroke. 35(9), 2200-5 (2004).

76. Kitaoka Y, Kitaoka Y, Kumai T, et al. Involvement of RhoA and possible neuroprotective effect of fasudil, a Rho kinase inhibitor, in NMDA-induced neurotoxicity in the rat retina. Brain Res. 1018(1), 111-8 (2004).

77. Bertrand J, Winton MJ, Rodriguez-Hernandez N, Campenot RB, McKerracher L. Application of Rho antagonist to neuronal cell bodies promotes neurite growth in compartmented cultures and regeneration of retinal ganglion cell axons in the optic nerve of adult rats. J. Neurosci. 25(5), 1113-21 (2005).

78. Bertrand J, Di Polo A, McKerracher L. Enhanced survival and regeneration of axotomized retinal neurons by repeated delivery of cell-permeable C3-like Rho antagonists. Neurobiol. Dis. 25(1), 65-72 (2007).

79. Honjo M, Tanihara H, Kameda T, Kawaji T, Yoshimura N, Araie M. Potential role of Rho-associated protein kinase inhibitor Y-27632 in glaucoma filtration surgery. Invest. Ophthalmol. Vis. Sci. 48(12), 5549-57 (2007).

80. Okumura N, Koizumi N, Kay EP, et al. The ROCK inhibitor eye drop accelerates corneal endothelium wound healing. Invest. Ophthalmol. Vis. Sci. 54(4), 2493-502 (2013). 
81. Waki M, Yoshida Y, Oka T, Azuma M. Reduction of intraocular pressure by topical administration of an inhibitor of the Rho-associated protein kinase. Curr. Eye Res. 22(6), 470-4 (2001).

82. Thieme H, Nuskovski M, Nass JU, Pleyer U, Strauss O, Wiederholt M. Mediation of calcium-independent contraction in trabecular meshwork through protein kinase $\mathrm{C}$ and rho-A. Invest. Ophthalmol. Vis. Sci. 41(13), 4240-6 (2000).

83. Tanihara H. Intraocular Pressure-Lowering Effects and Safety of Topical Administration of a Selective ROCK Inhibitor, SNJ-1656, in Healthy Volunteers. Arch. Ophthalmol. 126(3), 309 (2008).

84. Nakajima E, Nakajima T, Minagawa Y, Shearer TR, Azuma M. Contribution of ROCK in contraction of trabecular meshwork: Proposed mechanism for regulating aqueous outflow in monkey and human eyes. J. Pharm. Sci. 94(4), 701-708 (2005).

85. Wang R, Serle J, Kopczynski C. Effect of 0.6\% AR-12286 on Aqueous Humor Dynamics in 6 Normotensive Monkey Eyes. Invest. Ophthalmol. Vis. Sci. 50, 1465 (2009).

86. Mizuno K, Koide T, Fujieda J, et al. Ocular hypotensive and neuroprotective effects of K-115, a novel Rho-kinase inhibitor. Invest. Ophthalmol. Vis. Sci. 48, 4806 (2007).

87. Chen J, Runyan SA, Robinson MR. Novel ocular antihypertensive compounds in clinical trials. Clin. Ophthalmol. 5(1), 667-677 (2011).

88. Renieri G, Choritz L, Rosenthal R, Meissner S, Pfeiffer N, Thieme H. Effects of endothelin-1 on calcium-independent contraction of bovine trabecular meshwork. Graefe's Arch. Clin. Exp. Ophthalmol. 246(8), 1107-1115 (2008).

89. Ehrenreich $\mathrm{H}, \mathrm{Nau} T \mathrm{TR}$, Dembowski $\mathrm{C}$, et al. Endothelin b receptor deficiency is associated with an increased rate of neuronal apoptosis in the dentate gyrus. Neuroscience. 95(4), 993-1001 (2000). 
90. Yagami T, Ueda K, Sakaeda $\mathrm{T}$, et al. Effects of an endothelin B receptor agonist on secretory phospholipase A2-IIA-induced apoptosis in cortical neurons. Neuropharmacology. 48(2), 291-300 (2005).

91. Yagami T, Ueda K, Asakura K, et al. Human group IIA secretory phospholipase A2 induces neuronal cell death via apoptosis. Mol. Pharmacol. 61(1), 114-126 (2002).

92. Zhang $M$, Budak MT, Lu W, et al. Identification of the $A 3$ adenosine receptor in rat retinal ganglion cells. Mol. Vis. 12, 937-48 (2006).

93. Galvao J, Elvas F, Martins T, Cordeiro MF, Ambrósio AF, Santiago AR. Adenosine A3 receptor activation is neuroprotective against retinal neurodegeneration. Exp. Eye Res. 140, 65-74 (2015).

94. Inoue T, Yokoyoma T, Koike $\mathrm{H}$. The effect of angiotensin II on uveoscleral outflow in rabbits. Curr. Eye Res. 23(2), 139-43 (2001).

95. Yang H, Hirooka K, Fukuda K, Shiraga F. Neuroprotective effects of angiotensin II type 1 receptor blocker in a rat model of chronic glaucoma. Invest. Ophthalmol. Vis. Sci. 50(12), 5800-4 (2009).

96. Cullinane AB, Leung PS, Ortego J, Coca-Prados M, Harvey BJ. Renin-angiotensin system expression and secretory function in cultured human ciliary body nonpigmented epithelium. Br. J. Ophthalmol. 86(6), 676-83 (2002).

97. Kramkowski K, Mogielnicki A, Buczko W. The physiological significance of the alternative pathways of angiotensin II production. J. Physiol. Pharmacol. 57(4), 52939 (2006).

98. Santos RAS, Simoes e Silva AC, Maric C, et al. Angiotensin-(1-7) is an endogenous ligand for the G protein-coupled receptor Mas. Proc. Natl. Acad. Sci. U. S. A. 100(14), 8258-63 (2003). 
99. Vaajanen A, Vapaatalo H. Local Ocular Renin-Angiotensin System - A Target for Glaucoma Therapy? Basic Clin. Pharmacol. Toxicol. 109(4), 217-224 (2011).

100. Costagliola C, Verolino M, De Rosa ML, laccarino G, Ciancaglini M, Mastropasqua L. Effect of oral losartan potassium administration on intraocular pressure in normotensive and glaucomatous human subjects. Exp. Eye Res. 71(2), 167-71 (2000).

101. Nathanson JA, McKee M. Identification of an extensive system of nitric oxideproducing cells in the ciliary muscle and outflow pathway of the human eye. Investig. Ophthalmol. Vis. Sci. 36(9), 1765-1773 (1995).

102. Garcia E, Silva-Garcia R, Mestre H, et al. Immunization with A91 peptide or copolymer-1 reduces the production of nitric oxide and inducible nitric oxide synthase gene expression after spinal cord injury. J. Neurosci. Res. 90(3), 656-663 (2012).

103. McKinnon SJ, Lehman DM, Kerrigan-Baumrind LA, et al. Caspase activation and amyloid precursor protein cleavage in rat ocular hypertension. Investig. Ophthalmol. Vis. Sci. 43(4), 1077-1087 (2002).

104. Guo L, Salt TE, Luong V, et al. Targeting amyloid-beta in glaucoma treatment. Proc. Natl. Acad. Sci. U. S. A. 104(33), 13444-13449 (2007).

105. Doh SH, Kim JH, Lee KM, Park HY, Park CK. Retinal ganglion cell death induced by endoplasmic reticulum stress in a chronic glaucoma model. Brain Res. 1308, 158-166 (2010).

106. Bonifati DM, Kishore U. Role of complement in neurodegeneration and neuroinflammation. Mol. Immunol. 44(5), 999-1010 (2007).

107. Tezel G, Yang X, Luo C, et al. Oxidative stress and the regulation of complement activation in human glaucoma. Invest. Ophthalmol. Vis. Sci. 51(10), 5071-82 (2010). 
108. Ding QJ, Cook AC, Dumitrescu A V., Kuehn MH. Lack of immunoglobulins does not prevent C1q binding to RGC and does not alter the progression of experimental glaucoma. Investig. Ophthalmol. Vis. Sci. 53(10), 6370-6377 (2012).

109. Howell GR, MacNicoll KH, Braine CE, et al. Combinatorial targeting of early pathways profoundly inhibits neurodegeneration in a mouse model of glaucoma. Neurobiol. Dis. 71, 44-52 (2014).

110. Osborne NN. Pathogenesis of ganglion "cell death" in glaucoma and neuroprotection: focus on ganglion cell axonal mitochondria. Prog. Brain Res. 173, 339-52 (2008).

111. Ju W-K, Kim K-Y, Lindsey JD, et al. Intraocular pressure elevation induces mitochondrial fission and triggers OPA1 release in glaucomatous optic nerve. Invest. Ophthalmol. Vis. Sci. 49(11), 4903-11 (2008).

112. Tezel G. Oxidative stress in glaucomatous neurodegeneration: mechanisms and consequences. Prog. Retin. Eye Res. 25(5), 490-513 (2006).

113. Huang J, Li X, Li M, et al. Mitochondria-targeted antioxidant peptide SS31 protects the retinas of diabetic rats. Curr. Mol. Med. 13(6), 935-45 (2013).

114. Barber AJ, Lieth E, Khin SA, Antonetti DA, Buchanan AG, Gardner TW. Neural apoptosis in the retina during experimental and human diabetes. Early onset and effect of insulin. J. Clin. Invest. 102(4), 783-91 (1998).

115. Li J, Chen X, Xiao W, et al. Mitochondria-targeted antioxidant peptide SS31 attenuates high glucose-induced injury on human retinal endothelial cells. Biochem. Biophys. Res. Commun. 404(1), 349-56 (2011).

116. Fukiage C, Mizutani K, Kawamoto Y, Azuma M, Shearer TR. Involvement of phosphorylation of myosin phosphatase by ROCK in trabecular meshwork and ciliary muscle contraction. Biochem. Biophys. Res. Commun. 288(2), 296-300 (2001). 
117. Tian B, Geiger B, Epstein DL, Kaufman PL. Cytoskeletal involvement in the regulation of aqueous humor outflow. Invest. Ophthalmol. Vis. Sci. 41(3), 619-23 (2000).

118. Somlyo AP, Somlyo A V. Signal transduction and regulation in smooth muscle. Nature. 372(6503), 231-6 (1994).

119. Tokushige $\mathrm{H}$, Inatani $\mathrm{M}$, Nemoto $\mathrm{S}$, et al. Effects of topical administration of $\mathrm{Y}-39983$, a selective Rho-associated protein kinase inhibitor, on ocular tissues in rabbits and monkeys. Investig. Ophthalmol. Vis. Sci. 48(7), 3216-3222 (2007).

120. Yanoff M, Duker J. Ophthalmology. 2nd ed. Mosby, St Louis.

121. Wang R-F, Podos SM, Mittag TW, Yokoyoma T. Effect of CS-088, an angiotensin AT1 receptor antagonist, on intraocular pressure in glaucomatous monkey eyes. Exp. Eye Res. 80(5), 629-32 (2005).

122. Prasanna G, Krishnamoorthy R, Clark AF, Wordinger RJ, Yorio T. Human optic nerve head astrocytes as a target for endothelin-1. Investig. Ophthalmol. Vis. Sci. 43(8), 2704-2713 (2002).

123. Fernández-Durango R, Rollín R, Mediero A, et al. Localization of endothelin-1 mRNA expression and immunoreactivity in the anterior segment of human eye: expression of ETA and ETB receptors. Mol. Vis. 9, 103-9 (2003).

124. Choritz L, Machert M, Thieme H. Correlation of endothelin-1 concentration in aqueous humor with intraocular pressure in primary open angle and pseudoexfoliation glaucoma. Investig. Ophthalmol. Vis. Sci. 53(11), 7336-7342 (2012).

125. Tomida I, Pertwee RG, Azuara-Blanco A. Cannabinoids and glaucoma. Br. J. Ophthalmol. 88(5), 708-13 (2004).

126. Gagliano C, Longo A, Ortisi E, et al. Ocular hypotensive ef cacy and safety of oral palmytoilethanolamide (Visimast $\left.{ }^{\circledR}\right)$ : clinical study. Invest Ophthalmol Vis Sci. 51(988) 
(2010).

127. Chien FY, Wang R-F, Mittag TW, Podos SM. Effect of WIN 55212-2, a cannabinoid receptor agonist, on aqueous humor dynamics in monkeys. Arch. Ophthalmol. (Chicago, III. 1960). 121(1), 87-90 (2003).

128. Danesh-Meyer H V, Levin LA. Glaucoma as a neurodegenerative disease. J. Neuroophthalmol. 35 Suppl 1, S22-8 (2015).

129. Helmer C, Malet F, Rougier M-B, et al. Is there a link between open-angle glaucoma and dementia? The Three-City-Alienor cohort. Ann. Neurol. 74(2), 171-9 (2013).

130. Tamura $\mathrm{H}$, Kawakami $\mathrm{H}$, Kanamoto $\mathrm{T}$, et al. High frequency of open-angle glaucoma in Japanese patients with Alzheimer's disease. J. Neurol. Sci. 246(1-2), 79-83 (2006).

131. Ghiso JA, Doudevski I, Ritch R, Rostagno AA. Alzheimer's disease and glaucoma: mechanistic similarities and differences. J. Glaucoma. 22 Suppl 5, S36-8.

132. Tewari M, Quan LT, O’Rourke K, et al. Yama/CPP32 beta, a mammalian homolog of CED-3, is a CrmA-inhibitable protease that cleaves the death substrate poly(ADPribose) polymerase. Cell. 81(5), 801-9 (1995).

133. Tajiri S, Oyadomari S, Yano S, et al. Ischemia-induced neuronal cell death is mediated by the endoplasmic reticulum stress pathway involving CHOP. Cell Death Differ. 11(4), 403-15 (2004).

134. Tsutsumi S, Gotoh T, Tomisato W, et al. Endoplasmic reticulum stress response is involved in nonsteroidal anti-inflammatory drug-induced apoptosis. Cell Death Differ. 11(9), 1009-16 (2004).

135. Anastasopoulos E, Founti P, Topouzis F. Update on pseudoexfoliation syndrome pathogenesis and associations with intraocular pressure, glaucoma and systemic diseases. Curr. Opin. Ophthalmol. 26(2), 82-9 (2015). 
136. Ovodenko B, Rostagno A, Neubert TA, et al. Proteomic analysis of exfoliation deposits. Invest. Ophthalmol. Vis. Sci. 48(4), 1447-57 (2007).

137. Ritch R, Schlötzer-Schrehardt U. Exfoliation syndrome. Surv. Ophthalmol. 45(4), 265315.

138. Libby RT, Li Y, Savinova O V, et al. Susceptibility to neurodegeneration in a glaucoma is modified by Bax gene dosage. PLoS Genet. 1(1), 17-26 (2005).

139. Tenner AJ, Fonseca MI. The double-edged flower: roles of complement protein C1q in neurodegenerative diseases. Adv. Exp. Med. Biol. 586, 153-76 (2006).

140. Botto M, Dell'Agnola C, Bygrave AE, et al. Homozygous C1q deficiency causes glomerulonephritis associated with multiple apoptotic bodies. Nat. Genet. 19(1), 569 (1998).

141. Osborne NN, Lascaratos G, Bron AJ, Chidlow G, Wood JPM. A hypothesis to suggest that light is a risk factor in glaucoma and the mitochondrial optic neuropathies. Br. J. Ophthalmol. 90(2), 237-41 (2006).

142. Tezel G, Yang X. Caspase-independent component of retinal ganglion cell death, in vitro. Invest. Ophthalmol. Vis. Sci. 45(11), 4049-59 (2004).

143. Foster KG, Acosta-Jaquez HA, Romeo Y, et al. Regulation of mTOR complex 1 (mTORC1) by raptor Ser863 and multisite phosphorylation. J. Biol. Chem. 285(1), 8094 (2010).

144. Chong ZZ, Shang YC, Wang S, Maiese K. A Critical Kinase Cascade in Neurological Disorders: PI 3-K, Akt, and mTOR. Future Neurol. 7(6), 733-748 (2012).

145. del Olmo-Aguado S, Núñez-Álvarez C, Ji D, Manso AG, Osborne NN. RTP801 immunoreactivity in retinal ganglion cells and its down-regulation in cultured cells protect them from light and cobalt chloride. Brain Res. Bull. 98, 132-44 (2013). 
146. Kitaoka Y, Munemasa Y, Kojima K, Hirano A, Ueno S, Takagi H. Axonal protection by Nmnat3 overexpression with involvement of autophagy in optic nerve degeneration. Cell Death Dis. 4, e860 (2013).

147. Tezel G, Wax MB. Increased production of tumor necrosis factor-alpha by glial cells exposed to simulated ischemia or elevated hydrostatic pressure induces apoptosis in cocultured retinal ganglion cells. J. Neurosci. 20(23), 8693-700 (2000).

148. Ganapathy P, Perry R, Smith R, et al. Homocysteine-Mediated Modulation of Mitochondrial Dynamics in Retinal Ganglion Cells (RGCs). Invest. Ophthalmol. Vis. Sci. 52,2669 (2011).

149. Qi X, Lewin AS, Sun L, Hauswirth WW, Guy J. Suppression of Mitochondrial Oxidative Stress Provides Long-term Neuroprotection in Experimental Optic Neuritis. Investig. Opthalmology Vis. Sci. 48(2), 681 (2007).

150. Quigley HA, McKinnon SJ, Zack DJ, et al. Retrograde axonal transport of BDNF in retinal ganglion cells is blocked by acute IOP elevation in rats. Invest. Ophthalmol. Vis. Sci. 41(11), 3460-6 (2000).

151. Pease ME, McKinnon SJ, Quigley HA, Kerrigan-Baumrind LA, Zack DJ. Obstructed axonal transport of BDNF and its receptor TrkB in experimental glaucoma. Invest. Ophthalmol. Vis. Sci. 41(3), 764-74 (2000).

152. Schori H, Kipnis J, Yoles E, et al. Vaccination for protection of retinal ganglion cells against death from glutamate cytotoxicity and ocular hypertension: implications for glaucoma. Proc Natl Acad Sci U S A. 98(6), 3398-3403 (2001).

153. Johnson T V., Bull ND, Hunt DP, Marina N, Tomarev SI, Martin KR. Neuroprotective effects of intravitreal mesenchymal stem cell transplantation in experimental glaucoma. Investig. Ophthalmol. Vis. Sci. 51(4), 2051-2059 (2010). 
154. Ng TK, Fortino VR, Pelaez D, Cheung HS. Progress of mesenchymal stem cell therapy for neural and retinal diseases. World J. Stem Cells. 6(2), 111-9 (2014).

155. Jo SA, Wang E, Benowitz LI. Ciliary neurotrophic factor is an axogenesis factor for retinal ganglion cells. Neuroscience. 89(2), 579-591 (1999).

156. Fischer D, Pavlidis M, Thanos S. Cataractogenic lens injury prevents traumatic ganglion cell death and promotes axonal regeneration both in vivo and in culture. Invest. Ophthalmol. Vis. Sci. 41(12), 3943-54 (2000).

157. Olson L, Backlund EO, Ebendal T, et al. Intraputaminal infusion of nerve growth factor to support adrenal medullary autografts in Parkinson's disease. One-year follow-up of first clinical trial. Arch. Neurol. 48(4), 373-81 (1991).

158. Seiger A, Nordberg A, von Holst $\mathrm{H}$, et al. Intracranial infusion of purified nerve growth factor to an Alzheimer patient: the first attempt of a possible future treatment strategy. Behav. Brain Res. 57(2), 255-61 (1993).

159. Lambiase A, Aloe L, Centofanti M, et al. Experimental and clinical evidence of neuroprotection by nerve growth factor eye drops: Implications for glaucoma. Proc. Natl. Acad. Sci. U. S. A. 106(32), 13469-74 (2009).

160. Wang KC, Kim JA, Sivasankaran R, Segal R, He Z. P75 interacts with the Nogo receptor as a co-receptor for Nogo, MAG and OMgp. Nature. 420(6911), 74-8 (2002).

161. Domeniconi M, Cao Z, Spencer T, et al. Myelin-associated glycoprotein interacts with the Nogo66 receptor to inhibit neurite outgrowth. Neuron. 35(2), 283-90 (2002).

162. Zheng B, Ho C, Li S, Keirstead H, Steward O, Tessier-Lavigne M. Lack of enhanced spinal regeneration in Nogo-deficient mice. Neuron. 38(2), 213-24 (2003).

163. Fischer D. Counteracting the Nogo Receptor Enhances Optic Nerve Regeneration If Retinal Ganglion Cells Are in an Active Growth State. J. Neurosci. 24(7), 1646-1651 
(2004). 